\title{
TITLE:
}

\section{Lifelong Education and Libraries}

$\operatorname{AUTHOR}(\mathrm{S})$ :

CITATION:

Lifelong Education and Libraries. Lifelong education and libraries 2001, 1

ISSUE DATE:

2001-03

URL:

http://hdl.handle.net/2433/43576

RIGHT: 


\title{
Lifelong Education and Libraries
}

General Journal Information

Lifelong Education and Libraries is published annually as a forum for the international exchange of scholarly ideas in the lifelong education and library science fields.

Manuscripts: Manuscripts should be submitted to the Editors, Yoshitaka Kawasaki, Yasushi Maehira, and Yoko Watanabe, Lifelong Education and Libraries, Graduate School of Education, Kyoto University, Yoshida-Honmachi, Sakyo-ku, Kyoto, 606-8501, Japan.

\section{EDITORS}

Yoshitaka Kawasaki

Yasushi Maehira

Yoko Watanabe

\section{ASSISTANT EDITOR}

Kayoko Murakami

\section{ADOVISORY BOARD}

Ettore Gelpi Director of the thesis. University of Paris I, Consultant of UNESCO, Paris, France

Wu Jianzhong Deputy Director, Shanghai Library, Shanghai, People's Republic of China Hiroshi Kawai Professor of Library Science, Rikkyo (St. Paul) University, Tokyo, Japan Gloria Ramirez Professor, Universidad Nacional Autonoma, Mexico City, Mexico, D.F. Manfred Ringhofer Professor, Osaka Sangyo University, Osaka, Japan

Sumon Tuladhar UNICEF, Kathmandu, Nepal

Wayne A. Wiegand Professor of Library and Information Studies, University of WisconsinMadison, Wisconsin, USA

\section{EDITORIAL OFFICE MEMBERS}

\author{
Yoshitaka Kawasaki \\ Yasushi Maehira \\ Yoko Watanabe \\ Kayoko Murakami
}

The following copyright will be held by the Lifelong Education and Libraries: To require approval to reprint, contingent on author's approval, for tables and figures, and for articles reprinted in whole or in main parts. 